CLINICAL STUDY

\title{
Mutational analysis of the autoimmune regulator (AIRE) gene in sporadic autoimmune Addison's disease can reveal patients with unidentified autoimmune polyendocrine syndrome type I
}

\author{
Anette S Bøe ${ }^{1}$, Per M Knappskog ${ }^{2}$, Anne Grethe Myhre ${ }^{1,3}$, Jan I Sørheim ${ }^{4}$ and Eystein S Husebye ${ }^{1}$ \\ ${ }^{1}$ Division of Endocrinology, Institute of Medicine, ${ }^{2}$ Centre of Medical Genetics and Molecular Medicine, Haukeland University Hospital, N-5021 Bergen, \\ Norway, ${ }^{3}$ Department of Pediatrics, Akershus Central Hospital, N-1474 Nordbyhagen, Norway and ${ }^{4}$ Department of Medicine, Stord Hospital, \\ N-5400 Stord, Norway \\ (Correspondence should be addressed to Anette Bøe; Email: Anette.Boe@med.uib.no)
}

\begin{abstract}
Objective: To investigate whether patients with Addison's disease and polyendocrine syndromes have undiagnosed autoimmune polyendocrine syndrome type I (APS I).

Materials and methods: Forty patients with clinical manifestations resembling APS I and with autoantibodies typical of this condition were screened for Norwegian autoimmune regulator (AIRE) gene mutations.

Results: A 30-year old man who had developed Addison' s disease at the age of 12, but had no other components of APS I, was homozygous for the 1094-1106 deletion mutation in exon 8 of the AIRE gene, the most common mutation found in Norway.

Conclusions: APS I patients with milder and atypical phenotypes are difficult to diagnose on clinical grounds. Autoantibody analysis and mutational analysis of AIRE may therefore be helpful modalities for identifying these individuals.
\end{abstract}

European Journal of Endocrinology 146 519-522

\section{Introduction}

Autoimmune adrenocortical failure (Addison's disease) can be observed as an isolated entity or as part of an autoimmune polyendocrine syndrome (APS) (1, 2). APS I is an autosomal recessive disease which is directly associated with mutations in the autoimmune regulator (AIRE) gene $(3,4)$. The APS I phenotype is diagnosed from the presence of two of the triad of main components, namely Addison's disease, hypoparathyroidism and chronic mucocutaneous candidiasis. Patients often have several additional autoimmune manifestations and ectodermal dystrophies (2, 5, 6). Clinical symptoms typically appear in childhood and additional manifestations can develop throughout life $(5,6)$. A number of circulating autoantibodies against cytochromes involved in the biosynthesis of steroid hormones and against enzymes involved in neurotransmitter biosynthesis are found in patients (7-9). Autoantibodies against aromatic L-amino acid decarboxylase (AADC), side-chain cleavage enzyme (SCC) and $17 \alpha$-hydroxylase $(17 \mathrm{OH})$ are relatively specific for APS I patients (10-12).
The clinical presentation of APS I varies in terms of both the number of components and the age at presentation, even within the same family $(5,6)$. In a study on 20 Norwegian patients, the age at diagnosis of the first clinical manifestation ranged from 1 to 20 years and the length of time before these patients were subsequently identified as having APS I varied from 2 to 49 years. Patients may have only one of the major components or only some of the other minor components and therefore do not fulfil the diagnostic criteria of APS I. Mutational analysis of the AIRE gene provides a definitive diagnosis of APS I. Using DNA analysis of the common Norwegian AIRE mutations (6) and assays of autoantibodies, we investigated patients with APS I-like clinical manifestations for the presence of undiagnosed APS I.

\section{Materials and methods}

\section{Subjects}

From our register of patients with Addison's disease $(n=94), 40$ patients were selected on the basis of one of the following criteria: Addison's disease 
Table 1 Characteristics of the patients screened for mutations in autoimmune regulator (AIRE).

\begin{tabular}{|c|c|c|c|c|}
\hline Sex & Age (years) & Age at diagnosis of Addison's disease (years) & Manifestations & Autoantibodies \\
\hline M & 49 & 11 & $A$ & $210 \mathrm{H}$ \\
\hline $\mathrm{F}$ & 76 & 56 & $\mathrm{~A}, \mathrm{~T}, \mathrm{D}, \mathrm{G}$ & $210 \mathrm{H}$ \\
\hline M & 53 & 6 & $\mathrm{~A}, \mathrm{~T}, \mathrm{G}$ & Negative \\
\hline $\mathrm{F}$ & 39 & 4 & $A, D, G$ & Negative \\
\hline $\mathrm{F}$ & 74 & 68 & A, $T$ & $21 \mathrm{OH}, \mathrm{SCC}, 17 \mathrm{OH}$ \\
\hline M & 29 & 12 & A & SCC \\
\hline M & 19 & 13 & A & $210 \mathrm{H}$ \\
\hline M & 35 & 3 & A, D, G & $210 \mathrm{H}$ \\
\hline $\mathrm{F}$ & 47 & - & $\mathrm{T}, \mathrm{P}, \mathrm{G}$ & $210 H$, SCC \\
\hline $\mathrm{F}$ & 26 & - & $\mathrm{T}, \mathrm{HP}$ & Negative \\
\hline M & 35 & 12 & A & $21 \mathrm{OH}$ \\
\hline M & 60 & 12 & $A, G$ & $17 \mathrm{OH}$ \\
\hline $\mathrm{F}$ & 17 & 12 & A, D, coeliac & $210 \mathrm{H}$ \\
\hline $\mathrm{F}$ & 40 & 36 & $A, T, D, G$ & $21 \mathrm{OH}$ \\
\hline $\mathrm{F}$ & 30 & 19 & $\mathrm{~A}, \mathrm{~T}$ & $210 \mathrm{H}, \mathrm{SCC}$ \\
\hline M & 50 & 3 & A, $T$ & $21 \mathrm{OH}$ \\
\hline $\mathrm{F}$ & 56 & 41 & A, T, G & $210 \mathrm{H}, \mathrm{SCC}$ \\
\hline $\mathrm{F}$ & 80 & 34 & $\mathrm{~A}, \mathrm{~T}, \mathrm{G}$ & $210 \mathrm{H}$ \\
\hline $\mathrm{F}$ & 61 & 36 & $\mathrm{~A}, \mathrm{~T}, \mathrm{G}$ & $210 \mathrm{H}$ \\
\hline $\mathrm{F}$ & 55 & 26 & $\mathrm{~A}, \mathrm{~T}, \mathrm{G}, \mathrm{V}$ & $210 \mathrm{H}, 17 \mathrm{OH}$ \\
\hline $\mathrm{F}$ & 46 & 32 & $A, G$ & $210 \mathrm{H}, \mathrm{SCC}$ \\
\hline $\mathrm{F}$ & 80 & - & IF adrenal positive & Negative \\
\hline $\mathrm{F}$ & 36 & 27 & $\mathrm{~A}, \mathrm{P}$, candidiasis & $210 \mathrm{H}, 17 \mathrm{OH}$ \\
\hline $\mathrm{F}$ & 36 & 11 & A, T, Turner syndrome & $210 \mathrm{H}$ \\
\hline $\mathrm{F}$ & 27 & 29 & $\mathrm{~A}, \mathrm{~T}$, candidiasis & $21 \mathrm{OH}, 17 \mathrm{OH}$ \\
\hline M & 52 & - & V & Negative \\
\hline $\mathrm{F}$ & 44 & 28 & $A, D$ & $21 \mathrm{OH}, 17 \mathrm{OH}$ \\
\hline $\mathrm{F}$ & 36 & - & $\mathrm{D}$, IF testis positive & Negative \\
\hline M & 49 & 13 & A, T, G, D & $21 \mathrm{OH}$ \\
\hline $\mathrm{F}$ & 28 & 26 & $A, G$ & $210 \mathrm{H}, \mathrm{SCC}, 17 \mathrm{OH}$ \\
\hline M & 59 & 20 & A & $210 \mathrm{H}, \mathrm{AADC}$ \\
\hline $\mathrm{F}$ & 46 & 36 & A & AADC \\
\hline $\mathrm{F}$ & 47 & 22 & $A, P$ & $210 \mathrm{H}, 17 \mathrm{OH}, \mathrm{AADC}$ \\
\hline M & 22 & - & Candidiasis & Negative \\
\hline $\mathrm{F}$ & 70 & 44 & A & AADC \\
\hline $\mathrm{F}$ & 51 & 28 & $A, D$ & $21 \mathrm{OH}, \mathrm{AADC}$ \\
\hline $\mathrm{F}$ & 10 & 2 & $\mathrm{~A}, \mathrm{~T}$ & AADC \\
\hline M & 13 & $\overline{9}$ & A, D, T & $210 \mathrm{H}$ \\
\hline $\mathrm{F}$ & 8 & - & Candidiasis & Negative \\
\hline M & 11 & 8 & A & $21 \mathrm{OH}$ \\
\hline
\end{tabular}

A, Addison's disease; T, autoimmune thyroid disease; D, diabetes mellitus; G, gonadal failure; coeliac, coeliac disease; HP, hypoparathyroidism; IF, immunofluorescense; $21 \mathrm{OH}, 21$-hydroxylase; SCC, side-chain cleavage enzyme, $17 \mathrm{OH}, 17 \alpha$-hydroxylase; AADC, aromatic L-amino acid decarboxylase; $\mathrm{P}$, pernicious anemia; $\mathrm{V}$, vitiligo.

diagnosed at $<20$ years of age, autoantibodies against $\mathrm{AADC}, \mathrm{SCC}$ or $17 \mathrm{OH}$ and the presence of clinical manifestations resembling APS I. Clinical details are summarized in Table 1.

\section{Mutational analysis of AIRE}

Mutational analysis of exons 6 and 8 was performed as described previously (13). Exon 10 was amplified and sequenced using primers and conditions also described by others (13).

\section{Other methods}

In vitro transcription and translation followed by immunoprecipitation assays were used to determine the presence of autoantibodies as described previously (12).

\section{Results}

We identified one new APS I patient who was homozygous for the $13 \mathrm{bp}$ deletion mutation in exon 8 (1094-1106 del), the most common AIRE mutation in Norway (Fig. 1). The deletion was also confirmed by sequence analysis on two separate blood samples. In addition, both parents were heterozygous for this mutation (Fig. 1). We were unable to amplify exon 10 of the AIRE gene from three of the patients. From two of these three we could not collect enough DNA to perform the analysis of exon 10, whereas PCR analysis of one of these subjects revealed no amplicon of this region. We cannot therefore rule out the possibility of mutations in exon 10.

The patient was a 30-year-old man who was diagnosed with Addison's disease at the age of 12. He 


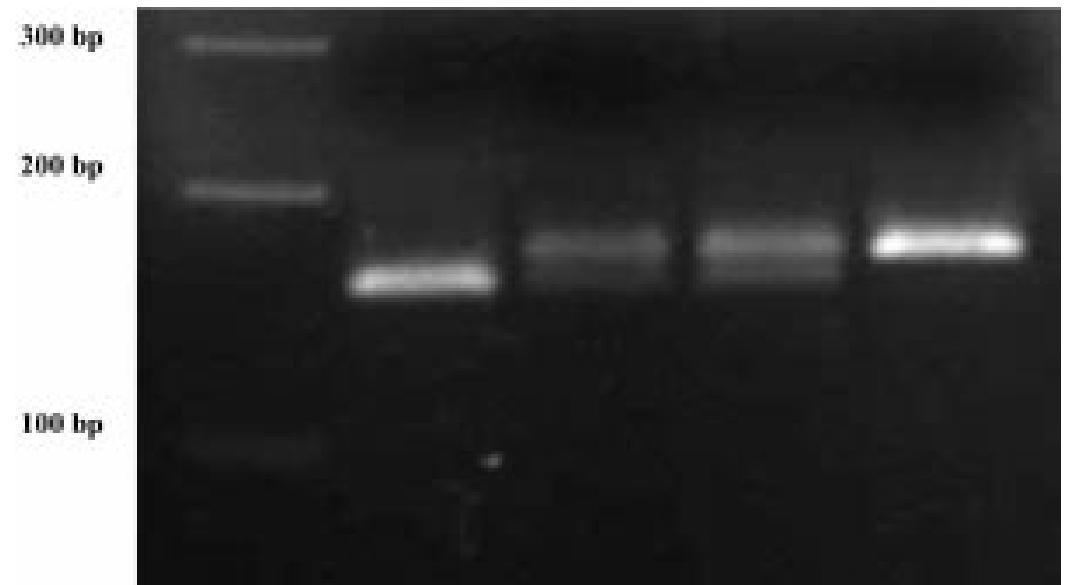

Figure 1 Agarose gel electrophoresis analysis of the 1094-1106 del mutation in exon 8 of the AIRE gene in the family with one affected member with APS I. Lane 1, molecular weight markers; lane 2, APS I patient homozygous for the $13 \mathrm{bp}$ deletion; lane 3, parent 1 who is heterozygous for the 13 bp deletion; lane 4, parent 2 who is heterozygous for the $13 \mathrm{bp}$ deletion; lane 5 , healthy control. reported none of the other endocrinopathies or ectodermal manifestations associated with APS I. After the diagnosis was made by DNA analysis of AIRE, the patient was again thoroughly examined by us and by an experienced dermatologist and by a dentist at the Faculty of Dentistry. No signs of other manifestations of APS I were found. He has two older sisters and an older brother who are healthy. His oldest sister died at the age of 4 during an acute varicella infection.

\section{Discussion}

The clinical presentation in APS I patients is very heterogeneous in terms of age at presentation, number of components and the time span between presentation of new manifestations $(5,6)$. Great variability is seen even among members of the same family (14). Therefore, we used DNA analysis of Norwegian mutations in AIRE (6) and assays of autoantibodies in an attempt to find previously unidentified APS I patients with milder and possibly atypical disease.

We found one such patient who was homozygous for the most common Norwegian mutation, the $13 \mathrm{bp}$ deletion in exon 8 (1094-1106 del) (6). This patient, a 30-year-old man, had had isolated Addison's disease since the age of 12 , but had no other components of APS I. He had autoantibodies against SCC and glutamic acid decarboxylase (GAD), autoantibodies which are found relatively commonly among these patients (6, $10)$, but are also seen in other autoimmune diseases (8).

In a similar study, British Addison patients were screened for the most common British AIRE mutation (1094-1106 del). One of 90 Addison patients and one of 576 healthy controls were found to be heterozygous (carriers) for the 1094-1106 del mutation in AIRE, but none were homozygous (15). Based on analysis of 817 individuals, another group concluded that the R257X and the 1094-1106 del mutations of AIRE, respectively, are so rare in the general population that they do not contribute to susceptibility for the more isolated autoimmune endocrine disorders like Addison's disease, insulin-dependent diabetes mellitus, Graves' disease and Hashimoto's thyroiditis (16).

Patients with a clear clinical picture of APS I, but with no mutations in exons of AIRE, have been reported (17). These individuals probably have mutations in introns or in promotor regions of this gene or may have large deletions, since the penetrance of APS I is thought to be $100 \%$ (18). No studies have reported disease-causing mutations on both alleles of AIRE in healthy patients (13, 16, 19). However, a recent report has described an Italian APS I family with a novel mutation in exon 6 and evidence of a dominant mode of inheritance (20).

It is important to make the diagnosis of APS I. These patients should be followed-up more closely than other patients with Addison's disease or APS II, since several life-threatening complications can occur such as autoimmune hepatitis, hypoparathyroidism and squamous cell carcinoma of the oral mucosa. Assay of autoantibodies (i.e. SCC, $170 \mathrm{H}, \mathrm{AADC}$ and GAD, and possibly also tryptophan hydroxylase (21) and tyrosine hydroxylase (22)) should be considered in patients who develop Addison's disease before the age of 20 and in patients with an APS I-like phenotype. Analysis of the hot-spot AIRE mutations should also be considered. We cannot exclude the possibility that the death of a girl in acute varicella infection was due to adrenocortical failure as a part of undiagnosed APS I.

\section{Acknowledgements}

We are grateful to all patients for collaboration and for donation of DNA samples. The excellent technical assistance of Elin Theodorsen and Wenke Trovik is gratefully acknowledged. This work was financially supported by Novartis, Bristol Myers-Squibb, Aagot Giertsen's Fund and Innovest. Professor Jan Magne 
Birkeland at the Faculty of Dentistry, University of Bergen is acknowledged for performing the dental examination, and Dr Arvid Nilsen at the Department of Dermatology, Haukeland University Hospital for the dermatological examination.

\section{References}

1 Oelkers W. Adrenal insufficiency. New England Journal of Medicine $19963351206-1212$.

2 Betterle C, Greggio NA \& Volpato M. Autoimmune polyglandular syndrome type 1. Journal of Clinical Endocrinology and Metabolism $1998831049-1055$.

3 The Finnish-German APECED Consortium, Autoimmune polyendocrinopathy-candidiasis-ectodermal dystrophy. An autoimmune disease, APECED, caused by mutations in a novel gene featuring two PHD-type zinc-finger domains. Nature Genetics $199717399-403$.

4 Nagamine K, Peterson P, Scott HS, Kudoh J, Minoshima S, Heino $\mathrm{M}$ et al. Positional cloning of the APECED gene. Nature Genetics $199717393-398$.

5 Ahonen P, Myllarniemi S, Sipila I \& Perheentupa J. Clinical variation of autoimmune polyendocrinopathy-candidiasis-ectodermal dystrophy (APECED) in a series of 68 patients. New England Journal of Medicine 1990322 1829-1836.

6 Myhre AG, Halonen M, Eskelin P, Ekwall O, Hedstrand H, Rorsman F et al. Autoimmune polyendocrine syndrome type 1 (APS I) in Norway. Clinical Endocrinology $200154211-217$.

7 Winqvist O, Karlsson FA \& Kampe O. 21-Hydroxylase, a major autoantigen in idiopathic Addison's disease. Lancet 1992339 $1559-1562$

8 Winqvist O, Gustafsson J, Rorsman F, Karlsson FA \& Kampe O. Two different cytochrome P450 enzymes are the adrenal antigens in autoimmune polyendocrine syndrome type I and Addison's disease. Journal of Clinical Investigation $1993922377-2385$.

9 Rorsman F, Husebye ES, Winqvist O, Bjork E, Karlsson FA \& Kampe O. Aromatic-L-amino-acid decarboxylase, a pyridoxal phosphate-dependent enzyme, is a beta-cell autoantigen. PNAS $1995928626-8629$.

10 Chen S, Sawicka J, Betterle C, Powell M, Prentice L, Volpato M et al. Autoantibodies to steroidogenic enzymes in autoimmune polyglandular syndrome, Addison's disease, and premature ovarian failure. Journal of Clinical Endocrinology and Metabolism $1996 \mathbf{8 1}$ $1871-1876$.

11 Krohn K, Uibo R, Aavik E, Peterson P \& Savilahti K. Identification by molecular cloning of an autoantigen associated with Addison's disease as steroid 17 alpha-hydroxylase. Lancet 1992339 $770-773$.

12 Husebye ES, Gebre-Medhin G, Tuomi T, Perheentupa J, LandinOlsson M, Gustafsson J et al. Autoantibodies against aromatic
L-amino acid decarboxylase in autoimmune polyendocrine syndrome type I. Journal of Clinical Endocrinology and Metabolism 199782 147-150.

13 Bjorses P, Halonen M, Palvimo JJ, Kolmer M, Aaltonen J, Ellonen P et al. Mutations in the AIRE gene: effects on subcellular location and transactivation function of the autoimmune polyendocrinopathy-candidiasis-ectodermal dystrophy protein. American Journal of Human Genetics $20006 \mathbf{6} 378-392$.

14 Myhre AG, Bjorses P, Dalen A \& Husebye ES. Three sisters with Addison's disease. Journal of Clinical Endocrinology and Metabolism $1998834204-4206$.

15 Vaidya B, Imrie H, Geatch DR, Perros P, Ball SG, Baylis PH et al. Association analysis of the cytotoxic $\mathrm{T}$ lymphocyte antigen-4 (CTLA-4) and autoimmune regulator-1 (AIRE-1) genes in sporadic autoimmune Addison's disease. Journal of Clinical Endocrinology and Metabolism $2000 \mathbf{8 5}$ 688-691.

16 Meyer G, Donner H, Herwig J, Bohles H, Usadel KH \& Badenhoop K. Screening for an AIRE-1 mutation in patients with Addison's disease, type 1 diabetes, Graves' disease and Hashimoto's thyroiditis as well as in APECED syndrome. Clinical Endocrinology 2001 $54335-338$.

17 Heino M, Peterson P, Kudoh J, Shimizu N, Antonarakis SE, Scott HS et al. APECED mutations in the autoimmune regulator (AIRE) gene. Human Mutation 200118 205-211.

18 Obermayer-Straub P \& Manns MP. Autoimmune polyglandular syndromes. Bailliere's Clinical Gastroenterology $1998 \quad 12$ 293-315.

19 Nithiyananthan R, Heward JM, Allahabadia A, Barnett AH, Franklyn JA \& Gough SC. A heterozygous deletion of the autoimmune regulator (AIRE1) gene, autoimmune thyroid disease, and type 1 diabetes: no evidence for association. Journal of Clinical Endocrinology and Metabolism 200085 1320-1322.

20 Cetani F, Barbesino G, Borsari S, Pardi E, Cianferotti L, Pinchera A et al. A novel mutation of the autoimmune regulator gene in an Italian kindred with autoimmune polyendocrinopathy-candidiasisectodermal dystrophy, acting in a dominant fashion and strongly cosegregating with hypothyroid autoimmune thyroiditis. Journal of Clinical Endocrinology and Metabolism 200186 4747-4752.

21 Ekwall O, Hedstrand H, Grimelius L, Haavik J, Perheentupa J, Gustafsson J et al. Identification of tryptophan hydroxylase as an intestinal autoantigen. Lancet 1998352 279-283.

22 Hedstrand H, Ekwall O, Haavik J, Landgren E, Betterle C, Perheentupa J et al. Identification of tyrosine hydroxylase as an autoantigen in autoimmune polyendocrine syndrome type I. Biochemical and Biophysical Research Communications 2000267 456-461.

Received 5 September 2001

Accepted 11 January 2002 